\title{
Reflections on the Moral Identity of Our Species in the Context of the Current World Pandemic
}

\author{
Qian Zhang, Shaogang Yang \\ School of English Education, Guangdong University of Foreign Studies, Guangzhou, China \\ Email: gwzhangqian@126.com
}

How to cite this paper: Zhang, Q., \& Yang, S. G. (2021). Reflections on the Moral Identity of Our Species in the Context of the Current World Pandemic. Advances in Applied Sociology, 11, 444-452. https://doi.org/10.4236/aasoci.2021.119039

Received: June 11, 2021

Accepted: September 13, 2021

Published: September 16, 2021

Copyright $\odot 2021$ by author(s) and Scientific Research Publishing Inc. This work is licensed under the Creative Commons Attribution International License (CC BY 4.0).

http://creativecommons.org/licenses/by/4.0/

(c) (i) Open Access

\begin{abstract}
In this era of a world pandemic, when global problems call for joint efforts across cultures and countries, establishing a community concerned with human destiny on the basis of a common moral identity is an urgent matter. The moral identity of our species refers to the fundamental moral values that are generally recognized by all humans as a species, starting from our biological origins and developing ethical contents throughout the long history of evolution. The construction of our moral identity as a species helps strengthen ties and cooperation between countries. This study shall consider the intercultural premises for defining a moral identity as a species in the context of the current pandemic as a common experience of humans, regardless of their culture. It also advocates for strengthening cultural inclusion to approach a more practical goal, namely practicing the species' moral identity and confronting a common human destiny under global challenges. In conclusion, the authors call for establishing specific discourses and strategies to improve intercultural respect and reciprocal recognition of our common moral identity.
\end{abstract}

\section{Keywords}

Citizenship, Community of Human Destiny, Moral Identity, Species Moral Identity

\section{Introduction}

After thousands of years of evolution, humans have developed various moral values, ethical principles and religious beliefs with both common and particular characteristics. When the unexpected COVID-19 virus struck the world, countries and governments adopted different measures and policies to fight it, which resulted in cultural clashes. Behind the conflicts, there are many questions re- 
garding morality and ethics for educators to consider. What could we learn from both gains and losses during this pandemic, when we are trying to reconstruct a new international order and build a community with a common destiny to solve the cross-cultural conflicts? That is an urgent task for researchers and educators in the field of morality.

\section{Civil Moral Identity in Cultural Conflicts}

\section{1) Forms of cultural conflicts during the pandemic}

The rapid spread of COVID-19 around the world in the past half a year triggers intense cultural conflicts in the following forms:

First, deeply-rooted social inequalities and economic marginalization have deprived a significant number of people in many countries of their necessities. In the outbreak of the pandemic, those people, in despair, have had to take risks to earn a living by crossing into the neighboring countries. Without the protection of effective measures, this process broadens the spread of the virus, therefore intensifies the conflicts between countries.

Second, the long-standing perception of individualism in western society makes many people ignore the government's ban, refuse to wear masks and protective equipment and even gather in mass for demonstrations. That makes the epidemic grow out of control in some countries, intensifying the conflicts between people in the country.

Furthermore, racism and racial discrimination have led to serious conflicts in some countries. In particular, there have been outbreaks, racial discrimination and attacks against Asians, Africans and Muslim Arabs in some Western countries, such as cyberbullying, comments full of racism, irresponsible dissemination of conspiracy theories concerning epidemic and xenophobic nationalism by politicians and leaders in some countries, all of which exacerbates cross-cultural conflicts during this period.

In today's world, the pandemic is not over, and various forms of cross-cultural conflicts are still emerging. The moral problems behind all of those are worth deeper reflection on the part of educators and researchers in this area.

\section{2) Citizens' moral identity and citizen morality}

Citizenship refers to a country's population recognized by the law with the right to participate in political processes. In recent years, scholars have focused their research on citizens' moral identity, arguing that moral identity can predict a citizen's moral behavior in a culture (Jia \& Krettenauer, 2017). However, the above proposal is limited to national perspectives, which is quite narrow and lacks the overall concern of the global community sharing a common human destiny.

Currently, when COVID-19 is spreading around the world, all governments have to take measures against it. However, due to different cultural practices, governments adopted different attitudes and measures towards the pandemic, which relates to the citizens' moral identity in their own cultures. The differenc- 
es are worth consideration. As some scholars have pointed out, "From the perspective of philosophy and ethics, the global risk of COVID-19 shows the urgency to build the ethical consciousness of the global community of common human destiny" (He, 2020).

The construction of a global community with a common destiny is closely related to the citizens' moral identity. Therefore, a moral identity recognized by all humans around the world is absolutely necessary for the construction of a human community. Citizens of every country could advocate for legal, sound and just social life, which, from a psychological point of view, is the emotional basis of a kind of citizens' moral identity recognized by all countries and cultures. It is also the basic demand for the creation of common moral values for the human community (Yang, 2010).

Citizen morality refers to the appropriate attitude and habits in public life that citizens, as members of a society, show to other members of society with equal political status (Zhou, 2008). In China, it refers to the moral principles and norms that all Chinese citizens should abide by in their social life.

In October 2019, the Central Committee of the Communist Party of China and the State Council jointly issued the "Outline for the Implementation of the Moral Construction of Citizens in the New era", which summed up the basic moral norms of Chinese citizens as "patriotic and law-abiding, courteous and honest, solitary and friendly, diligent and frugal, dedicated and devoted". Those norms become the core values leading the moral construction of socialist citizens in China. If we think from a global perspective, we find that the core features of the citizen morality in China, are also the moral identity that the whole world, as a human community of shared destiny, should pursue. In other words, citizen morality of one country is also closely related to the citizens' moral identity in a community of human destiny.

\section{3) Moral identity for Perfectionism}

When we take a look at history, we find that both in the East and West, citizens' moral identity in different countries share some common features.

In ancient China, philosophers believed that the ultimate goal of human life is to pursue perfectionism, in other words, the highest realm of virtue and thoughts. That was regarded as the most valuable social practice in the world. In the Confucian classic The Great Learning, it was said:

The way of the Great Learning is to show and develop the people's bright virtue of beauty and goodness within, and make clear away with outmoded conventions and practices, try to make the people with new ideas, and finally reach the highest realm of virtue and thoughts.

Coincidentally, in ancient Greece, Aristotle also believed that all communities, in the form of Polis, were set up with the same purpose, that is, to realize perfectionism. He said "the most valuable, noble and authoritative community of all the communities, must regard the pursuit of perfectionism as it ultimate goal" (Aristotle, 2003).

The foresight and sagacity of those ancient philosophers 2500 years ago, both 
in the East and West, is quite enlightening for us today. Those moral norms and ethical principles acknowledged by most members in both West and East set up the ethical basis for a citizens' moral identity for the global community of human destiny.

Western scholars believe that moral identity can predict people's moral behavior in Western culture, because moral identity is based on the community's culture. In fact, any nation or cultural identity, has the moral identity advocated by its community. By research into the nature of moral identity, it can predict its members' moral behaviors, to most extent.

In recent years, the Chinese government advocated for "One Belt, One Road" to set up a community of shared future. In order to achieve that goal, it advocates for a species moral identity that is recognized and accepted by all human across different cultures and nations.

Species moral identity refers to the fundamental moral values that are generally recognized by all human as a species starting from its biological origin and developing its ethical contents in long history of evolution. If we emphasize species moral identity, it leads to togetherness. Reversely, if we emphasize the differentiated moral identity, it leads to confrontation. That has been again and again proved by human history.

Although in the complex international context at present, it is quite difficult to achieve the proposed moral identity for the human community, many scholars still raised some moral qualities for citizens of human community. For example, in America, some put forward the following principles as politeness, harmony, honesty, self-control, tolerance, trust, compassion, responsibility, political effectiveness, cooperativeness, loyalty, courage, respect for the values, concern for common good, and other core civic values (Patrick, 1999; Arthur, 2005). In China, the government has also put forward 24 core values for Chinese citizens. Apart from these, no other country or scholar has proposed an overall set of principles and values by which all citizens of the human community should abide. Even more, the world is still in need of international organizations, laws and regulations to support these values. There is still a long way to go to build a moral identity unanimously acknowledged by global citizens.

\section{Species Moral Identity and Cultural Inclusion}

\section{1) Connection between moral identity and moral behavior}

Studies in Western moral psychology show the relationship between an individual's moral identity and his moral behavior, believing that, the former is a very good predictor of the latter.

For example, if one regards such moral values like integrity, compassion, fairness, respect, politeness, as the core of his/her identity, he/she will form a strong moral identity, which, as a result, pushes him/her to take actions consistent with his moral identity.

Therefore, through an individual's moral identity, we can predict what actions he will take in the context of morality. In other words, moral identity and moral 
behavior are closely related.

However, the above conception is far from reaching the standard of a moral identity for a community of shared future, because it only refers to the perspective of an individual. Since there is a lack of ethical consciousness for communities, when faced with problems that can only be solved through the joint efforts of all the countries, such as environmental pollution, natural disasters, ecological crisis and a pandemic like COVID-19 which broke out in early 2020 and lasts until now, it is impossible to take appropriate and unanimous moral actions.

Some countries have paid a high cost for that, which again, sends the topic of setting up a community of shared future into heated discussion.

\section{2) Possibility of establishing a moral identity for our species}

Although it is not easy to establish a moral identity for a human community, it is still possible.

When studying morality's cultural orientation, scholars attach great attention to how culture helps form some specific thinking patterns and promotes some specific moral values (Norenzayan \& Heine, 2005). It has been found that there may exist universally accepted basic moral principles. However, due to the great impact of different countries and cultures on morality, those basic moral principles change to cultural pressure at the national level. Thus, even if there are similar or identical moral identities, they are usually shown in different ways. Obviously, cultural factors must be taken into account while studying moral identities, which is a new research orientation in recent years.

Contemporary psychologists take questionnaires and empirical research in certain cultural groups to study their moral identity. However, some scholars have acutely pointed out that these moral attributes and characteristics are mostly Western moral values, which do not possess cultural inclusiveness. In order to find out more about the moral identities of the human community, we require an expansion in the range and the number of the objects of study (Miller, 2007). Therefore, some scholars believe that we should develop some culturally unbiased tools to measure and characterize moral identities. The first step is to find out the concept of "moral person" with archetypal significance from different cultures, especially from groups of the East and West, which shows great differences in cultures. Although this is a laborious and time-consuming study, there are still scholars who are headed in this direction. Jia conducted a cross-cultural comparative study between China and the United States. Results showed that there were some similar moral identities between those two cultures, but the identities were defined differently in terms of culture. Moral identities which can effectively predict people's moral behavior in American culture proved to be ineffective in Chinese culture (Jia, 2016).

Although Jia's research is quite promising, its scope is limited to Chinese and American cultural values, which makes it hard to illustrate the moral identities of the human community. Other scholars have also done similar research in their own countries and cultures, but due to the sample size, the cross-cultural study in moral psychology is still taking one individual culture as the target, in- 
stead of one with all cultures inclusive. In this sense, the study of moral identities needs the moral and cultural inclusion of the human community.

\section{Species' Moral Identities for a Community of Common Destiny}

\section{1) Species existence requiring species moral identity}

Taking a look at the history of biological evolution, we can clearly see that mankind has existed for millions of years as a "species" organized in the form of families, tribes, nations to countries. Mankind has been able to survive, live and evolve through social interaction. As early as more than 100 years ago, Marx clearly pointed out, "Mankind is a species, not only because man, both in practice and theory, takes 'species'-mankind and other species as its target... mankind takes itself as a living species because it exists as normal and free creatures".

Since mankind evolves as a species, it requires social interaction. Through interaction, humans have to identify a set of norms and values that are accepted and maintained by all members of the community, in order to fulfill the demands of their materialistic and psychological lives. Only in that way, will the community develop smoothly and its members live a happy life.

Before the industrial revolution in the West, moral identities developed and formed in the community of only one nation, country or culture, due to backward technology and infrequent communication between countries and cultures.

Since mid-1600, mankind developed so rapidly that there arose huge changes in the world economy and human societies, after two global revolutions.

The first globalization starts from the Bourgeois Revolution in 1640 and ends with two world wars in $20^{\text {th }}$ century, with developed countries' colonial robbery of Asian, African and Latin American countries.

The second globalization starts from the end of the Cold War, till the beginning of $21^{\text {st }}$ century, with Western developed countries, like America as the representative, establishing a series of international organizations and laws to protect their own interests.

However, with the fast evolution in globalization and progress in technological change, our cultural community as the foundation of the species of mankind, keeps developing and evolving.

Although there are nearly 200 countries and regions in the world today-very much like the Spring-Autumn and War Period in ancient China-the big world has gradually changed into a small global village.

Different countries and cultures start awakening in the fight against political, economic and cultural colonization directed by some Western developed countries. Globalization prioritized by Western developed countries is facing unprecedented challenges. "America First", which was proposed by the Trump administration, is a sign of anti-globalization. However, history is irreversible. With China's development as the second biggest economy, and the rapid development of BRICS and new emerging economies, a human community of shared destiny is coming into being. 


\section{2) Ethical thoughts on the moral identity of our species}

Although the concept of "a human community of shared destiny" provides soil for the moral identity of our species, it is still difficult to foresee its establishment, because that community is composed of and coexists with the specific countries and cultures (sub-community), and the moral identity of these sub-communities has a decisively restrictive effects on the moral behavior of its members.

From the different anti-COVID-19 measures adopted by countries, we can clearly see how they are influenced and constrained by deeply-rooted political ideology, as well as the moral identities of their culture. In such an era when globalization is irreversible, advocating for the establishment of a moral identity for the human community (species moral identities) is not only the historical mission, but also a major subject on which all of us need to focus.

First of all, the idea of a moral identity of the species is based on the existence of human kind as a species. On the one hand, it emphasizes the same destiny as human kind, sharing of benefits, bilateral cooperation and win-win strategy; on the other hand, it commits and respects the differences in cultures. In other words, species moral identity should not only consciously emphasize the most basic and universal moral values in the community of common human destiny, but also recognize the unique moral culture and values inherent in different countries and nations. However, we should be aware that in an era of globalization, these two aspects are not in binary opposition, but intrinsically consistent with each other. It requires different countries and cultures' autonomous recognition of our common human destiny, so that they can work together to protect the benefits of the human community as a whole.

Second, we need to establish the mechanism of respect and equal discussions among cultures, in terms of the moral identity of our species. In this era, symbiosis and competition exist in different cultures. If we do not establish a mechanism for discussion within the community, something that would show respect for different cultures, it will lead to a crisis in values concerning the species' moral identity, which would seriously hinder the construction of the community of common human destiny. The Confucian principle of "respect and honesty" in China embodies the profoundness in cultural respect, including etiquette, integrity, respect, loyalty and other moral values. This principle has important cultural enlightenment for the construction of the community of common human destiny. For example, etiquette between different cultures helps avoid disputes over values; honesty increases cultural trust; courtesy wins mutual respect; loyalty promotes harmonious relations. Therefore, in the process of building the community of common human destiny, we should make full use of the essence of our ancient cultural traditions and try our best to form and perfect the mechanism of discussion by respecting different cultures.

Third, it is imperative to strengthen the construction of the species' moral identity in the community of common human destiny. With the development of economic globalization, social information and network, no one, either a coun- 
try or a person-wherever it is and whatever religion or ideology she believes in-can exist outside the community of common human destiny. As Chinese Chairman Xi Jinping said, "No country can meet the challenges that human kind is facing now alone, nor can it retreat to a self-enclosed island". He therefore called on the world "that all peoples must work together to build a community of common human destiny and build a world of peace, security, and common prosperity; a world full of openness and tolerance, cleanness and beauty" (Xi, 2017).

However, some countries prioritize their individual interests and values over the common interests and values of all mankind, leading to constant conflicts and crises in the international community. The current outbreak of COVID-19 has sounded the alarm to the world, which tells us that the construction of the community of common human destiny should focus on the establishment of international organizations related to the community of a common human destiny, the formulation of the Constitution of this human community, as well as the implementation of the ethical rules, value consensus and related laws and regulations. Only in this way can we guide the country and the national community to coexist with the community of common human destiny, coordinate and progress together, achieve the species' moral identity of the community of common human destiny, and finally achieve the comprehensive development of human beings.

Finally, we need to practice and perfect the species' moral identity through moral education. In addition to discussion and cooperation between governments and organizations, education also takes responsibility. Creating a proper moral environment and a moral atmosphere will not only provide moral exemplars for the citizens in the community of common human destiny, but also enhance the species' moral identity in that community. Studies have found that people who often notice unethical events in life would form a bad impression of the moral environment of society. Instead, the experience of moral goodness in social life can promote people's moral identity and pro-social behavior (Aquino $\&$ McFerran, 2011). These findings pose adequate guidance for our moral education.

The moral identity of the species within the community of common human destiny must be achieved through education, but the effectiveness of education needs to be promoted by cooperation of the human community in moral education. It goes without saying that educational guidance goes hand in hand with the construction of social morality, and is the basis for the establishment of the species' moral identity of the community. Therefore, we should not only vigorously strengthen the education of our citizens' moral identity, and enhance the moral literacy of citizens, but also actively guide and promote education for the species' moral identity of the human community. This is a more difficult and long-term mission of the times than the economic mission of the community of common human destiny. It is also the moral and educational power that drives us, moral educators, to fight for a brighter future. 


\section{Funding}

This paper is part of the research results of the basic education research project "Empirical Research on Moral Judgment Ability of Chinese Private Middle School Students" supported by Huiyan Education Fund.

\section{Conflicts of Interest}

The authors declare no conflicts of interest regarding the publication of this paper.

\section{References}

Aquino, K., \& McFerran, B. (2011). Moral Identity and the Experience of Moral Elevation in Response to Acts of Uncommon Goodness. Journal of Personality and Social Psychology, 100, 703-718. https://doi.org/10.1037/a0022540

Aristotle (2003). Politics. (Y. Yi, \& D. H. Qin, Trans.). China People’s University Press.

Arthur, J. (2005). The Re-Emergence of Character Education in British Education Policy. British Journal of Educational Studies, 53, 239-254. https://doi.org/10.1111/j.1467-8527.2005.00293.x

He, L. (2020-05-25). Ethical Dimension of the Community of Common Destiny. Guangming Daily.

Jia, F. (2016). Moral Identity from Cross- and Bi-Cultural Perspectives. Ph.D. Thesis, Wilfrid Laurier University.

Jia, F., \& Krettenauer, T. (2017). Recognizing Moral Identity as a Cultural Construct. Frontier in Psychology, 8, 412. https://doi.org/10.3389/fpsyg.2017.00412

Miller, J. G. (2007). Cultural Psychology of Moral Development. In S. Kitayama, \& D. Cohen (Eds.), Handbook of Cultural Pscyhology (pp. 477-499). Guilford Press.

Norenzayan, A., \& Heine, S. J. (2005). Psychological Universals: What Are They and How Can We Know? Psychological Bulletin, 131, 763-781. https://doi.org/10.1037/0033-2909.131.5.763

Patrick, J. (1999). The Concept of Citizenship in Education for Democracy. USA: Education Resources Indormation Center.

Xi, J. P. (2017). Secure a Decisive Victory in Building a Moderately Prosperous Society in All Aspects and Strive for the Great Success of Socialism with Chinese Characteristics for a New Era. People's Publishing House.

Yang, S. G. (2010). Cultural Origin of Moral Values and Universality of Species Moral Values. Journal of Ideological and Theoretical Education, 26, 27-31.

Zhou, G. W. (2008). Historical Origin of Citizens' Ethical Perception. Central Compilation \& Translation Press. 